\title{
El Derecbo y la Aparición del Estado Inca
}

\author{
Por FRANKLIN PEASE G. Y.
}

\begin{abstract}
Al hablar de derecho entre los Incas hay que tomar un punto de partida y de relación distinto al que debe tenerse para estudiar el derecho contemporáneo. Hay que recordar que estamos analizando una institución de una cultura absolutamente distinta de la nuestra en que las relaciones entre divinidades y hombres, $\mathrm{y}$ aún entre hombres solamente, están revestidas de condiciones diferentes a las actuales. Mientras hoy día puede decirse que la obligación que la ley impone emana de ella misma, para los Incas la fuerza impositiva que la ley poseía le había sido otorgada por la Divinidad. Por esta razón fundamental es que debemos analizar la organización del estado incaico y resaltar especialmente los resultados referentes a la religión en cuanto estén vinculadas al derecho. Fero no sólo la religión va a darnos la clave para nuestro trabajo; como veremos luego la organización jurídica del país de los Incas alcanza su momento definitivo con la aparición y afianzamiento de! estado. El estudio de estas circunstancias nos dará la pauta - junto con el problema religioso_- para estudiar la idea que del derecho tuvieron los Incas.
\end{abstract}

La organización del estado es siempre una claye para iniciar el estudio del derecho de un pueblo. En aquellos conjuntos sociales donde se ha logrado el establecimiento de una estructura estatal respetuosa del hombreciudadano y se ha encontrado una resultante lógica en la organización de un sistema de gobierno llamado "democrático", se encontrará una justificación del derecho por la naturaleza misma del hombre que busca la justicia. En cambio en ciertos pueblos donde el estado está organizado teocráticamente, la ley se subordina a los intereses que el gobernante representa -real o supuestamente-, a la divinidad. De esta manera encontramos en los últimos una relación más duradera entre la ley y la religión. Prueba del primér tipo de estados es Atenas y también - con ciertas reservas- la república romana. Característico ejemplo de los segundos son el imperio chino, el Egipto faraónico y, en América los Mayas, los Aztecas y los Incas.

En el país de los Incas la vinculación estrecha entre religión y derecho aparece desde los primeros momentos legendarios. En las dos versiones tradicionales sobre la aparición del grupo humano quechua, la del lago Titicaca y de los hermanos Ayar, se confunde evidentemente las funciones de creador $u$ organizador del mundo (1), con las del primer legis- 
lador. Prácticamente todos los cronistas están de acuerdo en señalar al arquetipo mítico Manco Cápac como al primer sistematizador de un ordenamiento jurídico. Sarmiento de Gamboa (2) y el Inca Garcilazo de la Vega (3) establecen esta relación. El indio Juan Santa Cruz Pachacuti, cuya obra publicara por primera vez en 1879 don Marcos Jiménez de la Espada, reune en Apo Manco Cápac los atributos del ordenador jurídico (4) al mismo tiempo que lo considera "... enemigo de las huacas, y como tal los (sic) destruyó..." (5). Esta actitud de Santa Cruz frente a sus divinidades ancestrales no obedece más que a un afán de parecer católico sin posible tacha a los ojos de los españoles que gobernaban, para quienes la menor muestra de alejamiento del orden o la práctica religiosa convertían al individuo en un reo. Esta figura de Manco Cápac como ordenador jurídico tiene la función arquetípica que también encontramos en lo religioso; esta idea está confirmada por Garcilaso de la Vega, quien llega a decir que:

... los Reyes Incas, habiendo de establecer cualquiera leyes o sacrificios, así en lo sagrado de su vana religión como en lo profano de su gobierno temporal, siempre lo atribuyeron al primer Inca, Manco Cápac, diciendo que él las había ordenado todas, unas había dejado hechas y puestas en uso y otras en dibujo para que en adelante sus descendientes las perfeccionasen a sus tiempos..." (6).

La sorpresa que el Inca manifiesta al describir esta asombrosa clarividencia del primer gobernante que su tradición conservaba -el concepto de arquetipo que hoy se conoce y que Garcilaso no podía tener (aunque sí conoció el concepto platónico de arquetipo) - explica claramente la función sintetizadora que el primer Inca tiene a los ojos de la tradición oral. Los testimonios sobre la función ordenadora de Pachacútec en el mismo terreno legal son aún más claros que los que tenemos para Manco Cápac; así dice el padre Las Casas que "Puso ley y orden aquel rey Pachacuti..." (7) aunque Las Casas se refiere en ese trozo sólo a los matrimonios, sus palabras sintetizan las abundantes citas que los cronistas hacen de la obra reformadora de Pachacútec en el terreno jurídico (8).

La vinculación entre lo religioso y lo jurídico es reconocida por los historiadores del país de los Incas. Aunque, como bien anota Basadre, el fenómeno jurídico no siempre se identífica con el religioso; se trata más bien de una coexistencia (9). Baudin, en cambio, cree que la violación de la ley Inca era un verdadero sacrilegio, porque la ley era divina. "El juez no podía modificarla. Por el contrario, las reglas derivadas de las costumbres, y por eso variables según los lugares, se aplicaban con ligereza y podían ser interpretadas". (10). Pero esta afirmación del profesor francés puede dar lugar a erradas interpretaciones. Estamos plenamente de acuerdo en que la ley incaica compartía el carácter divino que el Inca poseía, pero esto no significaba que la ley en sí fuese divina ni que siempre su incumplimiento fuera un sacrificio (la referencia a la ley divina es, naturalmente, el concepto de tal que tenían los cronistas. Esta idea de la divinidad de la ley ha existido en todas las culturas. En cuanto al sacrilegio es 
también común; pero la idea que traen los cronistas es la cristiana, derivada del derecho romano modificado, y esta versión es la que Baudin utiliza. Aún no se ha precisado el alcance que sacrilegio tenía entre los Incas). Baudin cae aquí en lugares comunes a la Historia europea. Podemos dudar que el delito contra lo divino tenga las mismas características en la antigua y cristiana Europa que el país de los incas. No hay que olvidar que lo divino es más accesible al hatumruna incaico que el europeo popular; esto se nota especialmente en el hecho que la multiplicación de divinidades andinas permitía la existencia de dioses locales a los que el hombre del pueblo podía rendir público homenaje sin intermediarios. La actividad religiosa de un cristiano - siempre canalizada por una Iglesia- es diferente a la del hombre andino, al cual estaba permitido realizar cultos particulares al lado de los estatales de los que tampoco podía sustraerse. La liturgia cristiana medieval y moderna está casi íntegramente dirigida por los sacerdotes, mientras que los fieles tienen una actitud pasiva conservada en parte hasta hoy día. Los rituales incaicos -en cambio- permitían y aún obligaban la intervención popular. Aún el solemne Inti Raymi no podía realizarse sin la activa participación de la atenta multitud que lo presenciaba en la plaza más importante del Cuzco (11).

Es necesarjo, sin embargo, aclarar que la aparición de un derecho organizado entre los Incas no parece anterior a la constitución del estado, cosa que ocurre en la época atribuída a Pachacútec, luego de la guerra chanca. A eso y a la función arquetípica de este Inca se debe que en él se concentre una extraordinaria tarea legal, según los cronistas (12). Es indudable que antes que el Cuzco se organizara como on estado poderoso - la fase imperial la han llamado muchos- existió una organización jurídica, un conjunto de normas lógicamente consuetudinarias y arraigadas en los diferentes sectores de la población. La diferenciación era tal vez tajante entre las disposiciones de grupos o castas distintas $y$ todos tendrían la tendencia bien señalada a identificar el ordenamiento social que emanaba de dichas disposiciones con aquel orden ideal y arquetípico existente en el mundo divino. El cosmos (caos organizado por acción directa o indirecta de la divinidad) es siempre el modelo de la organización de las sociedades humanas. Es tal vez la razón de la adoración tributada a los personajes reales, aunque debe dejarse bien en claro que no es al hombre a quien se adora, sino al cargo, al poder divino hecho figura (13). La misma identificación que puede encontrarse al señalar -como lo hace Mircea Eliade que “...todo templo o palacio- y por extensión toda ciudad sagrada" o residencia real- es una "montaña sagrada", debido a lo cual se transforma en Centro (religioso)..." (14). La identificación que se anota entre los centros sagrados y las residencias reales -cuestión confirmada por los cronistas para el pueblo Inca- hace pensar en si la organización social estatal, de que el Inca, es cabeza, no es sino la repetición del mundo real $y$ arquetípico en que se desenvuelven las divinidades. La aparición del estado es entonces consecuencia directa de la organización ideal existente entre los dioses. No debe olvidarse que la diferenciación que hoy establecemos entre lo sagrado y lo profano no existe para el hombre primitivo. De esta manera puede comprenderse la 
relación que el hombre andino encontraba entre el Janan Pacha o mundo de los dioses celestes y el Cay Pacha o mundo de aquí, habitado por hombres, animales etc. (15). Dice Mircea Eliade que"... el mundo que nos rodea, en el cual sentimos la presencia y la obra del hombre - las montañas a que éste trepa, las regiones pobladas y cultivadas, los ríos navegables, las ciudades, los santuariog- tienen un arquetipo extraterrestre, concebido, ya como un plano", ya como una "forma", ya pura y simplemente como un "doble" (16). Esta visión arquetípica e ideal del mundo que origina el ordenamiento (jurídico) del estado terrestre, se realiza a partir de la época atribuída a Pachacútec. Aquí se notaría de igual modo una tendencia a organizar la sociedad, lo que se revela en las disposiciones ordenadoras emanadas de ésta época. Es muy difícil diferenciar, en el derecho primitivo, las meras disposiciones de orden público o policial de aquelllas concretamente legales y de los ordenamientos solamente religiosos. Es demasiado confusa la diferenciación entre los terrenos religiosos $\mathrm{y}$ jurídicos, como bien anota Basadre (17). También se aprecia claramente que en esta época se elabora un plan de trabajo - la tan decantada planificación, términos que muchos utilizan para la época Inca sin medir los alcances temporales de esta palabra y su concreta significación actual- Este ordenamiento es visible en los datos aportados por las crónicas y se puede identificar con la aparición del estado cuzqueño (18).

En el ordenamiento jurídico incaico llegado hasta nosotros por las crónicas encontramos dos épocas bien marcadas y que corresponden a los períodos políticos de Confederación cuzqueña y de Estado Inca; el primer periodo ubicado antes de la época de Pachacútec y el segundo deapciés de ella. Lo que más salta a la vista en las informaciones es la presencia, en el segundo período, de una complicada burocracia estatal que presta al mismo tiempo servicios judiciales. La justicia de la primera época debió estar regulada por los mismos consejos de ancianos que actuaban como gobernantes (19); debe pensarse entonces que el Cuzco era una población semejante a las que la rodean, en cuanto a su organización, y que la preeminencia que irá adquiriendo hasta la violenta expansión política contemporánea a la organización estatal de Pachacútec, obedeció a pactos con los grupos vecinos, a alianzas sanguíneas o a pequeñas victorias militares. Sólo el gran reto (al estilo de Toynbee) de la guerra chanca permite apreciar la "mayoría de edad" del naciente estado.

La aparición del estado significa, pues, un punto crucial en la Hiatoria del Derecho Incaico. A partir de entonces es este estado quien toma a su cargo la organización de la sociedad. Puede notarse que Pachacútec deja memoria de numerosas disposiciones que arrancan de la cuestión indudablemente religiosa de la división de la ciudad del Cuzco y del territorio ahora bajo su dominio, en las cuatro regiones o "suyos". María Rostworowski de Diez Canseco opina que esta división no pudo ser anterior a Pachacútec porque "... en reinados anteriores la Confederación Cuzqueña abarcaba sólo las regiones cercanas a la ciudad. El concepto de dividir el mundo conocido de la época, no podía existir antes de las grandes conquistas....." (20). Este es un raciocinio lógico, pero no ha ténido en cuenta que esta división del 
mundo que se afirma hizo Pachacútec corresponde a un arquetipo anterior. Lo que sí pudo hacer fué extender solamente esta división real a las nuevos: territorios.

Pero no sólo hay reformas de carácter administrativo o de demarcación política; en el terreno de la sucesión al poder se realizan entonces importantes reformas que analizaremos aparte. Sin embargo, puedo aclarar aquí que se aprecia en esta época y al lado de la afirmación de la estructura estatal, la designación del sucesor del gobernante. Podrá decirse contra esto que las crónicas hablan de una ininterrumpida sucesión monárquica desde Manco Cápac a Atahualpa; pero no debe olvidarse que es ingenuo aceptar esta versión y considerar dinástica la sucesión establecida por los cronistas, en realidad es una sucesión simbólica. La sucesión al poder en la primera época no pudo de ninguna manera estar revestida de los caracteres de solemnidad y orden que los cronistas le atribuyen, sobre todo por la falta de la organización estatal (21). La época primitiva, bien llamada de Confederación cuzqueña, la encontramos ocupada por diversos grupos de tribus establecidos en la zona vecina al Cuzco (22), que se encontraban unidas por vínculos arbitrarios $\mathrm{y}$ ocasionales; eran uniones basadas en alianzas muchas veces matrimoniales entre los individuos de los sectores dominantes en cada grupo; pero hay que dejar en claro que estas alianzas -aún las matrimoniales- no pueden entenderse de igual manera que las uniones entre Casas reales de la Europa medieval y moderna; pues es muy diferente la situación y estructura de una "familia real" a la manera europea y la de uno cualquiera de los grupos dominantes de una tribu o grupo de tribus de la Confederación de la zona del Cuzco.

Pero no es solamente en el aspecto sucesorio donde se manifiesta el ordenamiento legal surgente al mismo tiempo que la organización de una estructura estatal más o menos compleja y que requiere la presencia de un aparato legal mínimo que regule esta organización. Es natural, entonces, que la creación del aparato legal sea contemporánea a la afirmación del estado.

El concepto de derecho en el período de la Confederación cuzqueña tiene que ser, naturalmente distinto del que luego se adquirió en la época estatal. El hombre primitivo tiene una serie de procedimientos para averiguar dequé lado está la Justicia, entre ellos encontramos la adivinación y las orda. lias, las últimas consisten en un procedimiento mágico por el que la divinidad decide —en el caso de un delincuente- la inocencia o la culpabilidad. Estos procedimientos se justifican porque los delincuentes, para las sociedades primitivas, no son "indeseables", como lo anota Lévi-Bruhl, que quieren aprovecharse de la sociedad; sino que hay que tener en cuenta la posible presencia de un hechicero que se ha servido de procedimientos mágicos para lograr algo por medio y a través del "delincuente" y su delịto; en el ejemplo puesto por Lévi-Bruhl, el delincuente en cuestión es un ladrón (23). Es diferente, 'pues, en principio, el concepto de "delincuente". Respecto a las normas, encontramos también serias diferencias; no habiendo escritura y, por ende, norma escrita, el derecho sólo puede funcionar de manera consuetudinaria, "Las leyes que tenían a ellos no eran escriptas, porque el uso de las letras o auia llegado a ellos, no las conosian. Todos los delictos y negociós administraban y castigauan de memoria, por 
buena razón natural, haciendo luego executal lo que mandauan, sin remisión ningu(n)a" (24). Pero además vale la pena anotar que en la época de la Confederación cuzqueña, cuando aún no está afirmado el estado unipoderoso y cuando todavía está en plena gestación la clase nobiliaria militar cuya preponderancia hará posible el encubramiento del estado, puede suponerse varios canales de costumbres jurídicas que residían en los grupos distintos que originaron la primitiva Confederación. Sólo con la aparición y consolidación del estado cuzqueño se apreciará la unificación no sólo de esta legislación consuetidinaria, sino que aparecerán entonces una serie de funcionarios cuyas tareas están vinculadas a la administración de justicia.

Estos diversos "derechos" orales de los pueblos unidos en torno al Cuzco se podrian encontrar sintetizados en las disposiciones que emanax de los gobernantes de la llamada primera dinastía y especialmente en las que dicta el arquetipo primordial Manco Cápac (25). Sin embargo, las: crónicas aportan pocos datos concretos sobre estas disposiciones. Pero en esta época de Confederación, el gobierno debió estar en manos de grupos de ancianos, probables antecesores de los amautas de la época de apogeo: (26) . Los religiosos Anello Oliva y Martín de Murúa afirman que Manco Cápac reunió unas "cortes" (no olvidar aquí la influencia de la cultura europea en los cronistas; para ellos la palabra "cortes" se aplicaba a reuniones de notables semejantes a las de la edad media española); pero estas reuniones pueden ser identificadas con mayor propiedad con los consejos de ancianos que gobernaban los grupos confederados y que eran, en realidad, los representantes de la élite religiosa tradicional (27).

Lá relación que ya hemos mencionado entre la religión y el derecho de los Incas tiene su explicación. "El hombre primitivo-dice Van der Leeuw - cuya vida sigue siendo utilitaria, no necesitaba una representación especial para fines religiosos; la unidad social sigue siendo la unidad religiosa". (28). Y es que puede afirmarse sin reparos que la primera manera como se manifiesta la unidad de un grupo social es mediante la religión. De la misma manera encontramos que en los primeros momentos de la Confederación del Cuzco la élite sigue siendo la religiosa y es la encargada de las cuestiones judiciales, y eso no debe llamar la atención. Anotamos que en el primer período no hemos encontrado funcionarios cuya tarea principal fuera la administración de Justicia (o, por lo menos, una de las principales). No puede olvidarse la importancia mágica que tiene el hecho de consultar a la divnidad para cualquier función o acto que debe celebrarse. Entre los Incas es conocido el ritual de la callpa, adivinación realizada sobre las entrañas de un auquénido y que las crónicas relatan se realizara al morir Huayna Cápac para que la divinidad decidiera cual de los candidatos presentados para sucederle tenía mayor "derecho" al poder (299). La función sacerdotal ha estado largo tiempo ligada a la interpretación del derecho; así sucedió en Roma, donde “... (los sacerdotes) eran intérpretes del derecho y durante largo tiempo la jurisprudencia era su prerrogativa: Jus civile repositum in penetra pontificum". (30) y lo vemos en el país de los lncas, donde también la ordalía resuelve quién de los litigantes (se puedé usar el término por extensión convencional) tiene el derecho (31). Se explica que el sacerdote tenga esta función, que la divi- 
nidad le otorga, como lo anota el padre Cobo para los Incas, (32), porque la divinidad tiene el poder y el sacerdote es quien la representa (33); de alli a la facultad interpretativa de la ley, sólo hay un paso, y esto lo califica como el funcionario judicial más antiguo.

Otra vinculación entre la religión y el derecho está en la forma como ambos se expresan en sus momentos culminantes "El derecho se dice (ius dicere); la palabra de consagración une así los fenómenos de la religión con los del derecho. La relación jurídica de los hombres entre sí depende por completo de sus relaciones con el poder" (34). La palabra puede ser considerada así como el punto de enlace entre lo divino que la religión representa y el derecho que quiere imponer a los hombres el orden que la divinidad dispone.

Sobre las disposiciones concretas de este primer período hemos señalado yá que en las crónicas reina úna absoluta vaguedad. Se coincide en sindicar a Manco Cápac como al primer ordenador (35); pero los otros gobernantes o sinchis (Jefes militares) de la Confederación del Cuzco aparecen con muy leve tarea en lo jurídico. Así Mayta Cápac “... digen que los gouernó muy bien, haciendo ordenancas morales y leyes, prohibiendoles las malas costumbres $\&$, y anadiendoles (sic) otras cossas naturales, poniendoles en ejecución de las cossas de recogimiento de los yndios". (36).

En cambio, para la época estatal los ejemplos son mucho más abundantes. El Padre Las Casas atribuye a Pachacútec el nombramiento de los funcionarios llamados tocricoc o tucuyricoc, pero hay que tener muy en cuenta -inclusive para la Historia de Derecho Peruano inca- que los escritos del padre Bartolomé de Las Casas adolecen de base firme. El fraile historiador utilizó muchas veces fuentes de segunda mano y jamás estuvo en el Perú; sin embargo, muchas veces acierta, salvo en los detalles (37). Es Pachacútec -al decir de Cieza - el que iba dejando gobernadores o representantes en las provincias que conquistaba, para “..la administración de justicia......" (38). Posteriormente, Túpac Inca deja disposiciones concretas para que los "...gobernadores y jueces y demás ministros de la justicia no se descuidasen o tiranizasen con la ausencia del Inca..." (39). Estos pocos ejemplos y la gran cantidad de funcionarios que, entre otras tareas, administran justicia y que son creados u organizados en su trabajo a partir de la época estatal cuyo inicio se atribuye a Pachacúted, nos indica el período de organización de un aparato jurídico en el nuevo estado de los Incas del Cuzco.

\section{NOTAS}

(1) "...el hombre arcaico no conoce ningún acto que no haya sido planteado $y$ vivido anteriormente por otro, otro que no era un hombre. Lo que él hace. ja se hizo. Su vida es la repetición ininterrumpida de zestas inauguradas por otros. ELIADE, Mircea... EJ Mito Eterno Retorno... Buenos Aires, Emocé Editoras, 1959; p. 18.

"El acto (humano) no obtiene sentido, realidad, sino ẹn la medida que renueva una acción primordial". ELIADE, Loc. cit.

"...la realidad se adquiere exclusivamente por repetición o participación; todo lo que no tieno un modelo ejemplar estä "denprovisto de sentido", ea decir, 
carece de realidad. Los hombres tendrian, pues, la tendencia a hacerse arquetípicos y paradigmáticos" ELIADE... Op. cit.. p. 45.

(2) SARMIENio DE GAMBOA. Pedro... Segunda parte de la Historia General llamada. Indica la cual por mando del Excelentísimo Señor Don Francisco de Toledo, Virrey, Gobernador y Capitán General de los Reinos del Pirú y Mayordomo de la Casa Real de Castilla, compuso el Capitán... Buenos Aires, Emecé Editores, 1947, Cap. Xl, p. 118 y ss.

(3) GARCILASO DE LA VECA, EI Inca... Primera parte de los Comentarios Reales de los Incas, Edición' de la Universidad Nacional Mayor de San Marcos, Patronato del Libro Universitario. Ill Vols. Estudio preliminar y notas de José Durand. Lima, 1960.

(4) SANTA CRUZ PACHACUTI, Joan de... Relación de las antigüedades desde reino del Pirú... En: Colección de Libros y Documentos Referentes a la Historia del Perú T. IX, II Serie. Lima, Sanmarti, 1927.

(5) SANTA CRUZ PACHACUTI... Op. cit. p. 143.

(6) GARCILASO... Op. cit, Lib. II, Cap. IX, p. 156 deI T. I.

(7) LAS CASAS,. Fray Bartolomé de... De las antigüas gentes del Perú... En. Los pequeños grandes libros de Historia Americana. Serie I, Tomo XVI. Lima, Miranda, 1948, p. 136.

(8) MURUA, Fray Martín de... Historia General del Pirú, Origen y Descendencia de los Incas donde se trata de las guerras civiles suyas, como de la entrada de los Españoles... Edición de don Manuel Ballesteros-Gaibrois... Madrid, Imprenta de don Arturo Cóngora, 1962. Lib. II, Cap. del T. II.

(9) BASADRE, Jorge... Historia del Derecho Peruano. Biblioteca Peruana de Ciencias Juridicas y Sociales. Vol. I. Lima, Editorial Antena, 1937. p. 77.

(10) BAUDIN, Louis... La vida cotidiana en el tiempo de los últimos Incas... Buenos Aires, Hachette, 1962, p. 139.

(II) En realidad, en la liturgia cristiana he tomado en cuenta sólo el Sacrificio de la Misa, que puede realizarse sĭn la participación y aún sin la presencia de los fieles que la sigan. En cambio el lnti Raymi y otras fiestas principales de loa lncas si requerian la participación activa del pueblo.

(12) RCSTWOROWSKI DE DIEZ CANSECO, María... Pachacútec... Lima, Impr. Torres Aguirre, 1953. p.

(13) VAN DER LEEUW, Gervasius... Fenomenologia de la Religión... Mérico, Fondo de Cultura Económica... 1964. p. 112.

(14) ElIADE, Mircea... El Mito del Eterno Retorno... p. 25.

(15) GARCILASO, Op. cit... Lib. I, cáp. VII.

VALCARCEL, Luin E... Etnohintoria dol Perú Antizuo... Lima, Universidad 
Nacional Mayor de San Marco, 1959, p. 139.

VALCARCEL, Luis E... Machu Picchu... Editorial Universitaria de Buenos Aires. 1964.

IMBELLONI, José... La "weltzinschauung" de los amautas reconstruída: formas peruanas del pensamiento templario... Lima, Actas y Trabajos del XXVIl Congreso de Americanistas. Imp. Gil. 1942.

(16) ELIADE, Mircea p. 22.

(17) BASADRE, Op. Cit. p. 77.

(18) MANNHEIM, Karl... Ensayos de sociologia de la Cultura...Madrid, Aguilar, 19963. P. 143.

ROSTWOROWSKI. . . Op. cit.

(19) VALCARCEL Luis... Del Ayllu al Imperio... Lima, Garcilazo, 1925, II. parte.

(20) ROSTWOROWSKI... Op cit... p. 167. La autora no aclara ésa división del mundo si es posible aun antes de las grandes conquistas, porque se hace en un mundo ideal, un plano divino, sin embargo, real.

(21) Puede afirmarse que el cambio ordenado de gobernantes solo puede existir mediante una previa organización del Estado. El ejercicio del poder se presenta en los primeros momentos de la Confederación del Cuzco como una situación violenta, a pesar de la existencia de grupos de ancianos, que pueden ser identificados con los amautas de la época de apogeo, debido a que el poder en los momentos de emergencia era confiado a las manos más fuertes y eficaces de un sinchis o Jefe de Guerreros, encargado de solucionar militarmente el problema surgido.

(22) VALCARCEL... Del Ayllu al Imperio... p. p 68 y ss.

(23) LEVI-BRUHL. . O Op. cit... pp. 180, 181 .

(24) MURUA... op. cit... Lib. Il, cap. IV p. 38 del T. II.

(25) Garcilaso... Op. cit... Lib. I, cap. XV p. 123 del T. I. Lib. II, cap. IX p. 156 del T. I.

(26) MLLONES SANTA GADEA, Luis... El Amauta... Lima, 1964. Texto Mecanografiado.- Tesis (Profesor de Educación Secundaria) Pontificia Universisidad Católica del Perú. Facultad de Educación. 1963.

Pease G. Y., Franklin... Amaru Inca Yupanqui... Lima, 1964. Texto Mecanografiado.- Tesis (Bachiller en Humanidades) Pontificia Universidad Católica del Perú. Facultad de Letras, 1964.

(27) ANELlo Oliva, Juan... Historia del Reino y Provincias del Perú de suś Incas Reyes, Descubrimiento y Conquista por los Españoles de la Corona de. 
Castilla, con otras irregularidades concernientes a la Historia... Lima, Imp. y Librería de San Pedro, 1895, Lib. I, Cap. II, pp. 36 y 37.

MURUA... op. cit... Lib. I cap. (en blanco), p. 24 del Tomo I.

(28) VAN DER LEEUW, C... Fenomenología de la Religión... México, Fondo de Cultura Económica 1964. pág. 209.

(29) PEASE, G.Y. Franklin... Orígenes de la Guerra entre el Cuzco I Quito... En Revista Peruana de Cultura. Organo de la Comisión Nacional de Cultura No 4, Lima, Enero de 1965. p. 102.

PEASE, G.Y. Franklin... Causas Religiosas de la Guerra entre el Cuzco y Quito. En: Historia y Cultura. Organo del Museo Nacional de Historia. Vol. I, No I, Lima, 1965 p. 127 y ss.

(30) VAN DER LEEUW... Op. cit. pág. 209.

(31) LEVI-BRUHL, Lucien... La mentalidad primitiva... Buenos Aires, Edificaciones Leviatan, 1957 p. 199.

(32) COBO, S.J., Bernabé... Historia del Nuevo Mundo... En: Biblioteca de Autores españoles. T.s. XCII y XClI, Madrid Ediciones Atlas, 1964. Lib. I, Cap. IV p. 66 del T. II.

(33) VAN DER LEEUW... op. cit. p. 210.

(34) Vłn DER LEEUW... op. cit. p. 397.

(35) GARCILASO... op. cit... lib. I, cap. XXV, p. 123 del T. I. SANTA CRUZ PACHACUTEC Joan... op. cit... p. 142.

MURUA,... op. cit... lib. I, cap. (en blanco) p. 24 del T. I.

(36) SANTA CRUZ... of. cit.

(37) LAS CASAS .. op. cit... cap. XXIV, p. 130.

(38) CIEZA DE LEON, Pedro... Del Señorio de los Incas... Buenos Aires, Ediciones Argentinas Solar, 1943, Cap. LIII, p. 250.

(39) GARCILASO... op. cit... Lib. Cap. 1, pp. 95, 96 del t. III. 